\title{
Does insurance protect individuals from catastrophic payments for surgical care? An analysis of Ghana's National Health Insurance Scheme at Korle-Bu teaching Hospital
}

Juliet Okoroh ${ }^{1,2,3,4^{*}}$ (D), Doris Ottie-Boakye Sarpong ${ }^{5,6}$, Samuel Essoun ${ }^{2}$, Robert Riviello ${ }^{1}$, Hobart Harris ${ }^{7}$ and Joel S. Weissman ${ }^{1}$

\begin{abstract}
Background: According to the World Health Organization, essential surgery should be recognized as an essential component of universal health coverage. In Ghana, insurance is associated with a reduction in maternal mortality and improved access to essential medications, but whether it eliminates financial barriers to surgery is unknown. This study tested the hypothesis that insurance protects surgical patients against financial catastrophe.

Methods: We interviewed patients admitted to the general surgery wards of Korle-Bu Teaching Hospital (KBTH) between February 1, 2017 - October 1, 2017 to obtain demographic data, income, occupation, household expenditures, and insurance status. Surgical diagnoses and procedures, procedural fees, and anesthesia fees incurred were collected through chart review. The data were collected on a Qualtrics platform and analyzed in STATA version 14.1. Fisher exact and Student T-tests were used to compare the insured and uninsured groups. Threshold for financial catastrophe was defined as health costs that exceeded 10\% of household expenditures, 40\% of non-food expenditures, or $20 \%$ of the individual's income.

Results: Among 196 enrolled patients, insured patients were slightly older [mean 49 years vs 40 years $P<0.05$ ] and more of them were female [ $65 \%$ vs $41 \% p<0.05]$. Laparotomy $(22.2 \%)$ was the most common surgical procedure for both groups. Depending on the definition, $58-87 \%$ of insured patients would face financial catastrophe, versus 83-98\% of uninsured patients (all comparisons by definition were significant, $p<.05$ ).

Conclusion: This study - the first to evaluate the impact of insurance on financial risk protection for surgical patients in Ghana - found that although insured patients were less likely than uninsured to face financial catastrophe as a result of their surgery, more than half of insured surgical patients treated at KBTH were not protected from financial catastrophe under the Ghana's national health insurance scheme due to out-of-pocket payments. Government-specific strategies to increase the proportion of cost covered and to enroll the uninsured is crucial to achieving universal health coverage inclusive of surgical care.
\end{abstract}

Trial registration: Registered at www.clinical trials.gov identifier NCT03604458.

Keywords: Catastrophic health expenditures, Surgical care, Universal health coverage, Ghana

\footnotetext{
* Correspondence: Jokoroh@gmail.com

${ }^{1}$ Brigham and Women's Hospital, Center for Surgery and Public Health, Boston, MA, USA

2Department of Surgery, Korle-Bu Teaching Hospital, Accra, Ghana

Full list of author information is available at the end of the article
}

(c) The Author(s). 2020 Open Access This article is distributed under the terms of the Creative Commons Attribution 4.0 International License (http://creativecommons.org/licenses/by/4.0/), which permits unrestricted use, distribution, and reproduction in any medium, provided you give appropriate credit to the original author(s) and the source, provide a link to the Creative Commons license, and indicate if changes were made. The Creative Commons Public Domain Dedication waiver (http://creativecommons.org/publicdomain/zero/1.0/) applies to the data made available in this article, unless otherwise stated. 


\section{Background}

\section{Essential and emergency surgery in universal health} coverage

It is estimated that $11-33 \%$ of the global burden of disease can be treated surgically; and this includes conditions related to cancer, obstetrics, congenital anomalies, and injury [1-4]. Yet, access to affordable healthcare remains a significant challenge globally. An estimated 3.7 billion individuals are at risk for catastrophic health expenditures (CHEs) due to surgical care, with a disproportionate burden in Sub-Saharan Africa and South-East Asia [5]. In May 2015, the World Health Assembly passed resolution 68.15, which called for the recognition of emergency and essential surgery as integral components of achieving universal health coverage (UHC) [6]. The goal was to improve access, financial risk protection, as well as the responsiveness of health systems in averting disability and productivity loss due to surgical conditions. Pivotal to these efforts has been the growing emphasis of the role of insurance in strengthening health systems. Prepayment schemes such as health insurance effectively pool risk and can protect households against unforeseen health shocks [7]. In fact, health insurance has been associated with a reduction in out-of-pocket expenditures (OOPEs) in Low-Middle Income Countries (LMICs) like Indonesia, Mali, China, India, Columbia, and Rwanda [8, 9]. With ongoing recommendations by the Lancet Commission on Global Surgery to develop national surgical plans in LMICs that provide $100 \%$ coverage against $\mathrm{CHE}(\mathrm{s})$ by 2030 , it is important to understand how health insurance schemes are designed to improve access to surgical care, particularly in countries undergoing health care reform [10].

\section{The experience of Ghana with universal health coverage} Ghana is a low middle income country with a population of 27 million people whose national health insurance scheme (NHIS) was implemented in 2003 [11]. NHIS is a government-sponsored mandatory insurance plan which is funded by the National Health Insurance Levy, a value added tax on all goods and services in the country [11]. This comprises $75 \%$ of its funding; the rest is from premiums, social security deductions, and registration fees [11-13]. NHIS covers $95 \%$ of conditions affecting Ghanaians and includes a variety of inpatient and outpatient services in surgery, obstetrics, general medicine, and emergency care [14]. Premiums are assessed based on ability to pay and typically range from 7.2 Ghana Cedis (US\$2.88) to 48 Cedis (US\$19.18) [15]. Premium exemptions exist for specific groups such as individuals above 70 years of age, the physically or mentally disabled, pregnant women, children [15], Social Security and National Insurance Trust SSNIT pensioners, indigents, and recipients of Government of Ghana cash grant [16]. This comprises close to $60 \%$ of the insured population who are exempt from paying premiums and registration fees. As of 2017, 35\% of the Ghanaian population was actively enrolled in the scheme with ongoing plans by the government to expand enrollment of the uninsured [17]. NHIS has been praised for its efforts in achieving equity and inclusion in health insurance schemes in LMICs and has served as a model for many countries in Sub-Saharan Africa that are undergoing health reform [18].

\section{Impact of insurance on health costs and outcomes in Ghana}

Analysis of the NHIS of Ghana over the past 10 years has demonstrated a positive impact on maternal health, with mother's more likely to receive antenatal care, to deliver at an institution, and to have assistance from a skilled birth attendant [19-25]. In addition, insured members are more likely to visit clinics, seek formal care when ill, and are more likely to obtain prescriptions [14]. With respect to the costs of healthcare, the probability of a household incurring CHEs was 4.2 times less likely for the insured than for the uninsured, although, insurance did not eliminate all direct costs associated with treatment [26]. In a prior systematic review, we found studies reporting up to $18 \%$ of insured households in Ghana would face financial catastrophe due to health costs [27]. In addition, gaps do exist in the coverage of medicines and supplies [27]. Although these studies provide the foundation for understanding the impact of NHIS on cost and utilization, there has been no study to date on the impact of NHIS on financial risk protection and cost of surgical care. Given the current emphasis of the role of surgery in UHC, our objective in this study was to test the hypothesis that insurance makes a difference in out-of-pocket expenditures for surgical care and $\mathrm{CHE}(\mathrm{s})$ by comparing rates of financial catastrophe for insured versus. Uninsured surgical patients at a single institution, the Korle-Bu Teaching Hospital (KBTH).

\section{Methods}

\section{Study site/population}

KBTH, founded in 1923, is the largest tertiary teaching hospital and the major referring hospital in Ghana. The hospital is situated in the southwestern part of Accra, the capital of Ghana. The hospital treats patients referred from centers all over Ghana and neighboring West African countries. Inhabitants are mostly urban or suburban with a small proportion of rural and slum dwellers. The Department of Surgery at KBTH has four general surgical units and additional wards encompassing orthopedic surgery, plastic surgery, urology, and neurosurgery. In 2016, a total of 7941 operations were performed; $33 \%$ in trauma, $30 \%$ in general surgery, $12 \%$ 
pediatric surgery, $8 \%$ neurosurgery, $6 \%$ urology, and 5\% in ophthalmology/oral maxillary facial surgery. The top three general surgery diagnoses in 2016 were symptomatic hernia, appendicitis, and breast cancer [28].

\section{Study design}

We conducted a cross-sectional survey of a random sample of patients who were admitted and discharged on the general surgery ward between February 1st 2017 and October 1st 2017 in the Department of General Surgery at $\mathrm{KBTH}$.

\section{Sampling method}

Efforts were made to sample across all four general surgical wards to obtain a representative sample of inpatients. Data collection consisted of two essential components: First, prior to discharge, patients on the general surgery wards were interviewed by two trained research assistants using a questionnaire developed based on the 2014 Ghana Demographic Health Survey and administered in the respondent's language [29]. It included modules on the respondent's demographic profile (age, ethnicity, income, employment status, occupation), socio-economic status, household characteristics (number of people in the household, sex of head of household, number of children, household expenditures on food, non-food expenditures), dwelling characteristics, as well as assets ownership. The health utilization module included number of hospitalizations during the last 3 months, number of out-patient visits, and the presence of chronic medical conditions [29]. Participants were also interviewed to collect payment information and receipts for items not billed by the surgical department but incurred as part of the hospitalization. This included payments for laboratory tests, imaging, and medicines billed by other departments or an outside facility. From this, we calculated the total cost to the patient for the hospitalization. Non-medical costs (indirect costs) were calculated as the cost of transportation to the facility and estimated lost wages, both obtained via the respondent's interview. The lost wages were derived from the average daily wages, obtained from the respondent's interview, multiplied by the length of stay for the hospitalization, obtained from the hospital record. The questionnaire is available in the appendix. The second component was a chart review and abstraction by the research assistants to obtain all costs of inpatient surgical care. From the hospital record, the primary surgical and any medical diagnoses were obtained as well as all procedures performed. Procedural fees, anesthesia fees, consultation fees, supplies, accommodations fees, and all hospital costs incurred were collected. The surgical cost minus NHIS payments was considered the OOPE for the insured at the surgery department level. The same analysis was repeated for charges outside the surgery department. The uninsured paid $100 \%$ of all costs as outof-pocket payments. The OOPEs are defined from the patient's perspective, i.e. the cost to the patient or the amount paid by the patient to the provider i.e. the hospital for all related health expenses that is not reimbursed by NHIS.

\section{Sample size}

For the primary comparison of financial catastrophe by insurance status, we assumed the insured would be less likely to make catastrophic payments. Previous studies on non-surgical respondents indicated that $6 \%$ of the insured compared to $28 \%$ of the uninsured made catastrophic payments [27]. Using this difference and a sample ratio of insured to uninsured respondents of 3 to $1,80 \%$ power, and a $95 \%$ confidence interval at the level of 0.05 yielded a sample size of 98 participants ( 25 uninsured, 73 insured) to detect a significant difference in financial catastrophe by insurance status. This sample size was calculated using the OpenEpi, Version 3 (2008) open source calculator-Proper [30].We sampled 203 respondents in order to have power for further subgroup analysis and to account for the possibility of nonresponse. A total of 196 patients had complete variables of interest (96\% response rate) and were included in the final analysis.

\section{Data description and analysis}

We used Stata 14.0 to generate frequencies, means and proportion utilizing the Fisher Exact tests. Multiple logistic regression models were used to obtain the relationships between financial catastrophe, and sociodemographic and clinical characteristics. An alpha level of 0.05 was used to determine the statistical significance. We analyzed all available observations and records. Observations and records with missing information on specific variables of interest were excluded from the analysis. Lastly, the principal component analysis was used to generate a household wealth index using 22 household living items including dwelling characteristics, access to utilities, and ownership of household items.

Statistical analysis was conducted at the individual and household levels. At the individual level, we examined the impact of NHIS on OOPEs. The OOPEs for the insured were calculated as the sum of: 1) total direct surgery department cost minus calculated payments to be made by NHIS and 2) payments made to other departments and facilities. For the uninsured, NHIS made no contributions and this was the total direct medical cost. Indirect costs were obtained from the transportation cost and calculated lost wages (individual's reported daily wage multiplied by the length of hospital stay). We compared the mean OOPEs between the insured and 
uninsured using descriptive statistics. We also compared the means of the socioeconomic and clinical characteristics between the insured and uninsured using Student $t$ tests. Fisher Exact tests were used to identify and compare the frequencies of all variables between the insured and uninsured.

At the household level, we explored the impact of NHIS on financial catastrophe using accepted definitions in the literature [31-35]. OOPEs were considered catastrophic if they exceeded $10 \%$ of annual total household expenditures, $20 \%$ of the individual's income, or $40 \%$ of non-food expenditures. Multiple regression models were developed to identify associations between financial catastrophe and socio-demographic and clinical characteristics. The questionnaire was administered and data collected through Qualtrics platform software by research assistants using a secured tablet. Data from the review of the hospital records and payment receipts for all costs incurred were also collected in Qualtrics platform software. The data were managed in Microsoft Excel 2014 and analyzed using Stata 14.1. An alpha level of 0.05 was used to determine the statistical significance.

\section{Permission and ethical considerations}

We sought ethical approval from both the University of California San Francisco and Korle-Bu Teaching Hospital. Permission was further obtained from the Department of the General Surgery at KBTH. Informed consent was also obtained from all participants in the study in order the ensure confidentiality by not disclosing any personal identifiers or names in data capturing, analysis and report writing.

\section{Results}

\section{Background characteristics}

There were 127 (65\%) respondents in the insured group and 69 (35\%) in the uninsured group. In terms of demographic and household characteristics, only age, sex, marital status, and number of children differed significantly between the two groups (Tables 1 and 2). Of note, $36 \%$ of the respondents were unemployed; they reported ill health, being retired, and educational activities as reasons for not working. The average monthly income was GH\& 754.0 (167 USD) and this did not differ by insurance status (Table 3). Average monthly expenditures were GHC 841 (186 USD), and non-food expenditures were GH\$ 620 (138 USD). On average, the insured and uninsured were similar in terms of community factors, such as distance to the nearest healthcare facility, although the insured made, on average, three visits to a health facility and the uninsured made two visits in the 3 months preceding the survey $(p=0.003)$ (Table 4$)$. The most common operation performed was a laparotomy (22\%) due to 1) intestinal obstruction, 2) peritonitis from perforated peptic ulcer/viscus, and 3) obstructive jaundice. The next most common operations were appendectomy (14\%) and inguinal hernia repair (10\%). Other procedures performed such as extremity or soft tissue surgery accounted for $13.0 \%$ of all procedures performed. Thirteen percent of respondents did not require a surgical procedure. There was no significant difference in the number and types of operations performed by insurance status.

\section{Direct and indirect costs of surgical care}

Table 5 presents the mean direct costs and indirect costs of surgical care by insurance status. The average departmental cost per patient for surgical care with a procedure was GHC 997 (\$222 USD) and without a procedure was GHC 478.3 (\$106 USD). Average cost of ancillary services, which included medicines, laboratory tests, and imaging, was GHष 1079 (\$240 USD). The average total direct cost of surgical care (direct OOPE) was GH\$ 2819 (626 USD). The insured paid 1.74 times less than the uninsured [GHष 2239 (\$497 USD) vs GH4 3887 (\$863 USD) $(p=0.0001)]$. The non-medical expenditures which included costs such as transportation costs and indirect costs such as lost wages - were GH4 234 (\$52.0 USD) on average and did not differ by insurance status $(p=0.657)$.

\section{Catastrophic health expenditures by insurance status}

Table 5 depicts financial catastrophe by insurance status using total OOPE, defined as payment in excess either of $20 \%$ of the individual's income, $10 \%$ of household expenditure, or $40 \%$ of non-food expenditures. On average, in our study population, the insured spent $39 \%$ of their estimated annual income on surgical care, whereas the uninsured spent $61 \%(p<0.04)$. We also found significant differences in the percentage of individuals making catastrophic payments by insurance status measured at different catastrophic thresholds. Using the $20 \%$ of individual income definition, $63 \%$ of the insured compared to $83 \%$ of the uninsured made catastrophic payments $(p<0.02)$. Using the $10 \%$ of the household expenditure definition, $87 \%$ of the insured compared to $98 \%$ of the uninsured made catastrophic payments $(p<0.008)$. Finally, using the $40 \%$ of subsistence expenditures definition, $58 \%$ of the insured compared to $94 \%$ of the uninsured made catastrophic payments $(p<0.001)$.

\section{Determinants of catastrophic health expenditures}

The multiple logistic regression estimates for all individuals demonstrated that significant determinants of CHEs are insurance status, having a surgical procedure, education attainment, and household wealth index. The results also showed that participating in NHIS reduces the probability of incurring CHEs. At the income level, 
Table 1 Background characteristics of study respondents

\begin{tabular}{|c|c|}
\hline Variables & Total \\
\hline \multicolumn{2}{|c|}{ Individual Characteristics \% (N) } \\
\hline \multicolumn{2}{|l|}{ Age (years) } \\
\hline Mean age & $47.2(S D \pm 1.188)$ \\
\hline$<25$ & $9.2 \%(18)$ \\
\hline $25-39$ & $24.5 \%(48)$ \\
\hline $40-69$ & $54.6 \%(107)$ \\
\hline$\geq 70$ & $11.7 \%(23)$ \\
\hline \multicolumn{2}{|l|}{ Sex } \\
\hline Male & $43.9 \%(86)$ \\
\hline Female & $56.1 \%(110)$ \\
\hline \multicolumn{2}{|l|}{ Ethnicity } \\
\hline Akan & $45.9 \%(90)$ \\
\hline Ga-Dangme & $23.5 \%(46)$ \\
\hline Ewe & $15.3 \%(30)$ \\
\hline Other & $15.3 \%(30)$ \\
\hline \multicolumn{2}{|l|}{ Marital Status } \\
\hline Never married & $20.4 \%(40)$ \\
\hline Currently married & $54.1 \%(106)$ \\
\hline Formerly married & $25.5 \%(50)$ \\
\hline \multicolumn{2}{|l|}{ Education } \\
\hline None & $11.2 \%(22)$ \\
\hline Primary & $26.0 . \%(51)$ \\
\hline Secondary & $42.9 \%(84)$ \\
\hline Tertiary & $19.9 \%(39)$ \\
\hline \multicolumn{2}{|l|}{ Employment Status } \\
\hline Unemployed & $36.2 \%(71)$ \\
\hline Employed & $63.8 \%(125)$ \\
\hline \multicolumn{2}{|l|}{ Occupation } \\
\hline Unemployed & $36.2 \%(71)$ \\
\hline Formal & $11.2 \%(22)$ \\
\hline Informal & $52.5 \%(103)$ \\
\hline \multicolumn{2}{|l|}{ Had a Procedure } \\
\hline Yes & $83.2 \%(163)$ \\
\hline No & $13.3 \%(26)$ \\
\hline Missing & $7.5 \%(7)$ \\
\hline \multicolumn{2}{|c|}{ Household Characteristics (mean) } \\
\hline Household size & $6.2(S D \pm 0.348)$ \\
\hline Number of children & $2.8(S D \pm 0.140)$ \\
\hline \multicolumn{2}{|c|}{ Sex of the house-hold head \%(N) } \\
\hline Male & $66.8 \%(131)$ \\
\hline Female & $18.4 \%(36)$ \\
\hline Missing & $14.8 \%(29)$ \\
\hline
\end{tabular}

uninsured members were six times more likely to incur CHEs for surgical care (OR 5.52; 95\% CI: 1.70-17.92) than the insured. For those living at the subsistence level, the uninsured were 16 times more likely to incur CHEs. Although factors such as age $>40$, female sex, being married, or working in the informal sector were associated with an increased likelihood of CHEs, none were statistically significant at the 0.05 alpha level.

\section{Discussion}

Our study-which examines the extent to which Ghana's NHIS protects individuals needing surgical care from financial catastrophe-shows that surgery is still unaffordable for more than $60 \%$ of insured patients seen at KBTH. This is a significant problem because one in every three respondents lives within the lowest wealth quintile and risk impoverishment as a consequence of paying for surgery. The costs associated with receiving surgical care at $\mathrm{KBTH}$, for the insured, constitute 33\% of the GDP per capita income as of 2016 (\$1507 USD) [36]. Likewise, OOPEs for the insured at KBTH constitute $60 \%$ of their total health expenditures, which greatly exceeds the $\mathrm{WHO}$ recommendations for OOPEs not to exceed more than $20 \%$ of total health expenditures $[37,38]$.

We found that insurance was not associated with a difference in the cost of ancillary services such as medicines, laboratory testing, and imaging that are included in the NHIS. The NHIS medicine list includes 517 medications that are part of the WHO list of essential medications, which are supposed to be covered free at the point of care $[39,40]$. Furthermore, routine laboratory tests and diagnostics such as ultrasound are supposed to be covered [41]. The findings we observed could in part be because the KBTH pharmacy does not accept NHIS payments and often patients have to obtain medicines outside the hospital [ 42]. Potential explanations for this phenomenon reported in the literature include anecdotal evidence of patients being told that the NHIS medicines are out of stock, poor reimbursement to the pharmacy by NHIS, and selection bias towards patients paying out of pocket [43]. Medicines such as antibiotics and pain medications, which are on the NHIS medicines list, but often not comprehensively covered, are essential components of surgical care and access to these medication needs to be addressed.

NHIS reimbursed on average $40 \%$ of the total cost of surgical care, which is based on the G-DRG. Anesthesia fees including the consultation fees and the cost of the anesthetic drugs are not reimbursed at the hospital level. This is a significant barrier because the vast majority of cases performed at $\mathrm{KBTH}$ in general surgery require anesthesia support. The anesthetic drugs are obtained from the pharmacy by the anesthesiologist and billed to the patient at the end of the procedure. This represents 
Table 2 Bivariate analysis of health insurance status of respondents by background characteristics

\begin{tabular}{|c|c|c|c|}
\hline \multirow[t]{2}{*}{ Variables } & \multicolumn{2}{|c|}{ Health insurance status $(N=196)$} & \multirow{2}{*}{$\begin{array}{l}P \text {-value } \\
\text { (Fisher } \\
\text { exact } \\
\text { test) }\end{array}$} \\
\hline & Insured $65 \%(N=127)$ & Uninsured 35\% $(N=69)$ & \\
\hline \multicolumn{4}{|l|}{ Age (years) } \\
\hline$<25$ & $6.3 \%(8)$ & $14.5 \%(10)$ & \multirow[t]{4}{*}{0.034} \\
\hline $25-39$ & $20.4 \%(26)$ & $31.9 \%(22)$ & \\
\hline $40-69$ & $59.1 \%(75)$ & $46.4 \%(32)$ & \\
\hline$\geq 70$ & $14.2 \%(18)$ & $7.2 \%(5)$ & \\
\hline \multicolumn{4}{|l|}{ Sex } \\
\hline Male & $35.4 \%(45)$ & $59.4 \%(41)$ & \multirow[t]{2}{*}{0.002} \\
\hline Female & $65.6 \%(82)$ & $41.6 \%(28)$ & \\
\hline \multicolumn{4}{|l|}{ Ethnicity } \\
\hline Akan & $41.7 \%(53)$ & $53.6 \%(37)$ & \multirow[t]{4}{*}{0.496} \\
\hline Ewe & $16.6 \%(21)$ & $13.1 \%(9)$ & \\
\hline Ga-Dangme & $25.2 \%(46)$ & $20.3 \%(14)$ & \\
\hline Other & $16.5 \%(30)$ & $13.0 \%(9)$ & \\
\hline \multicolumn{4}{|l|}{ Marital Status } \\
\hline Never married & $15.0 \%(19)$ & $30.4 \%(21)$ & \multirow[t]{3}{*}{0.037} \\
\hline Currently married & $57.5 \%(73)$ & $47.8 \%(33)$ & \\
\hline Formerly married & $27.5 \%(35)$ & $21.8 \%(15)$ & \\
\hline \multicolumn{4}{|l|}{ Education } \\
\hline None & $11.8 \%(15)$ & $10.1 \%(7)$ & \multirow[t]{4}{*}{0.434} \\
\hline Primary & $28.3 \%(36)$ & $21.8 \%(15)$ & \\
\hline Secondary & $38.6 \%(49)$ & $50.7 \%(35)$ & \\
\hline Tertiary & $21.3 \%(27)$ & $17.4 \%(12)$ & \\
\hline \multicolumn{4}{|l|}{ Employment Status } \\
\hline Unemployed & $38.6 \%(49)$ & $31.9 \%(22)$ & \multirow[t]{2}{*}{0.437} \\
\hline Employed & $61.4 \%(78)$ & $68.1 \%(47)$ & \\
\hline \multicolumn{4}{|l|}{ Occupation } \\
\hline Unemployed & $38.6 \%(49)$ & $31.9 \%(22)$ & \multirow[t]{3}{*}{0.608} \\
\hline Formal & $10.2 \%(13)$ & $13.0 \%(9)$ & \\
\hline Informal & $51.2 \%(65)$ & $55.1 \%(38)$ & \\
\hline \multicolumn{4}{|l|}{ Had a Procedure } \\
\hline Yes & $87.8 \%(101)$ & $85.3 \%(52)$ & \multirow[t]{2}{*}{0.644} \\
\hline No & $12.2 \%(14)$ & $14.7 \%(9)$ & \\
\hline \multicolumn{4}{|c|}{ Household Characteristics (mean) } \\
\hline House-hold size & 6.5 & 5.6 & 0.21 \\
\hline Number of children & 3.1 & 2.2 & 0.003 \\
\hline \multicolumn{4}{|c|}{ Sex of household head } \\
\hline Male & $76 \%(84)$ & $82.5(47)$ & \multirow[t]{2}{*}{0.43} \\
\hline Female & $23 \%(26)$ & $18(10)$ & \\
\hline
\end{tabular}

a potential opportunity for intervention. For example, NHIS should cover the cost of anesthesia care, and costs might be saved by improving the procurement practices at KBTH.
Our study has several limitations which must be acknowledged. Close to $70 \%$ of respondents in our study were insured, which is almost twice the national average for Ghana and could represent a selection bias toward 
Table 3 Welfare Characteristics of the Respondents

\begin{tabular}{|c|c|c|c|c|}
\hline \multirow[t]{2}{*}{ Variables } & \multicolumn{2}{|c|}{ Health insurance status } & \multirow{2}{*}{$\begin{array}{l}P \text { - value } \\
\text { (Fisher's } \\
\text { exact } \\
\text { test) }\end{array}$} & \multirow[t]{2}{*}{$95 \% \mathrm{Cl}$} \\
\hline & Insured & Uninsured & & \\
\hline \multicolumn{5}{|l|}{ Individual Ghל̧ (\$USD) } \\
\hline Mean monthly income & $744.5(78)$ & $800.64(47)$ & 0.529 & $680.5-850.7$ \\
\hline \multicolumn{5}{|l|}{ House-hold Ghל (\$USD) } \\
\hline Mean monthly total expenditures & $904.3(127)$ & 726.9 (69) & 0.027 & 766.3-917.4 \\
\hline Mean monthly non-food expenditures & 668.4. (127) & $531.4(69)$ & 0.033 & $559.6-680.8$ \\
\hline \multicolumn{5}{|l|}{ Household wealth index $\%(N)^{a}$} \\
\hline Poor & $33 \%(43)$ & $38 \%(26)$ & 0.471 & \\
\hline Middle & $30 \%(38)$ & $35 \%(24)$ & & \\
\hline Rich & $36 \%(46)$ & $28 \%(19)$ & & \\
\hline
\end{tabular}

Source: Authors; computed from individual survey data, 2017

Ghana Cedis (Ghc) 4.5=\$1.0USD, March 2018

T- test for equal means, significant level at 0.05

a'Based on principal component analysis of the response of individuals to 22 items which included households' dwelling characteristics, access to utilities and ownership of consumer durables. $(\mathrm{N})$ number of respondents

insurance, and thus limits extrapolation of our findings to the national level [44]. This is partly because the Greater Accra region is among the top three regions with the highest insurance penetration [44]. In addition, $\mathrm{KBTH}$, the largest hospital in Ghana, has a diverse socio-economic background, which makes it a representative sample of urban Ghana; but our findings may not be generalizable to rural areas. Next, we did not collect data on how households coped with making payments and the contributions of relatives and non-government institutions in reducing the financial burden of care. This could be significant because based on our calculation, $60 \%$ of patients would likely not be able to afford surgery without other means of hardship financing, despite having health insurance. In fact, one out of three households in Africa and Southeast Asia pay for medical expenses by borrowing, liquidation of assets, or selling $[45,46]$. This type of hardship financing also increases the probability that a household would be in further debt as a result of seeking healthcare. Moreso, we were unable to collect indirect non-medical cost data associated with care-givers as our study focused on sampling the experience of patients primarily. Finally, further studies are needed to compare costs of surgery

Table 4 Health Systems and Community Factors by Insurance Status

\begin{tabular}{|c|c|c|c|}
\hline \multirow[t]{2}{*}{ Variable } & \multicolumn{2}{|c|}{ Health insurance status } & \multirow[t]{2}{*}{$P$-value (Fischer's exact test) } \\
\hline & Insured & Uninsured & \\
\hline \multicolumn{4}{|l|}{ Regular health care provider \% (N) } \\
\hline Yes & 86.5 (109) & $76.1(51)$ & 0.074 \\
\hline No & $13.5(17)$ & $23.9(16)$ & \\
\hline \multicolumn{4}{|l|}{ Type of health facility } \\
\hline Tertiary/Teaching Hospital & $45.7(58)$ & $42.0(29)$ & 0.871 \\
\hline Public/Quasi/Private Hospital & $19.7(25)$ & $23.2(16)$ & \\
\hline Polyclinic & $28.3(36)$ & $30.4(21)$ & \\
\hline Other & $6.3(8)$ & $4.4(3)$ & \\
\hline \multicolumn{4}{|l|}{ Distance to home facility } \\
\hline$<1 \mathrm{KM}-10 \mathrm{KM}$ & $11.8(15)$ & $13.0(9)$ & 0.526 \\
\hline $11-15 \mathrm{KM}$ & $16.6(21)$ & $17.4(12)$ & \\
\hline $16-20 \mathrm{KM}$ & $41.7(53)$ & $49.3(34)$ & \\
\hline$>20 \mathrm{KM}$ & $29.9(38)$ & $20.3(14)$ & \\
\hline \multicolumn{4}{|l|}{ Healthcare utilization } \\
\hline Mean number of health facility visits (in last three months) & 3.1 & 2.2 & 0.003 \\
\hline
\end{tabular}


Table $\mathbf{5}$ Cost of Surgical Care and Financial Catastrophe by Insurance Status

\begin{tabular}{|c|c|c|c|}
\hline & \multicolumn{2}{|c|}{ Health insurance status } & \multirow{2}{*}{$\begin{array}{l}P \text {-value } \\
\text { (Fischer's } \\
\text { exact } \\
\text { test) }\end{array}$} \\
\hline & Insured & Uninsured & \\
\hline \multicolumn{4}{|l|}{ Out of pocket (OOP) expenditures Ghל (\$USD) } \\
\hline Mean OOP health expenditure (direct medical cost for surgery) & $997.1(203)$ & $2,860.0$ & $<0.001$ \\
\hline Mean OOP health expenditures (direct medical cost for ancillary services) & $1100(244)$ & $1,039.0$ & 0.667 \\
\hline Mean OOP non-medical cost/indirect health costs (transportation and lost wages) & $243(54)$ & 218.0 & 0.657 \\
\hline Total OOP health expenditures (direct \& indirect costs) & $2238.7(497)$ & 3,887.5 (863) & $<0.001$ \\
\hline \multicolumn{4}{|l|}{ Financial Catastrophe $\%^{\mathrm{a}, \mathrm{b}}$} \\
\hline Percent total OOP out of individual income & $40 \%$ & $61 \%$ & 0.037 \\
\hline Percent total OOP out of house-hold expenditures & $25 \%$ & $53 \%$ & $<0.001$ \\
\hline Percent total OOP out of subsistence expenditures ${ }^{c}$ & $67 \%$ & $142 \%$ & $<0.001$ \\
\hline \multicolumn{4}{|l|}{ Percentage of individuals incurring catastrophic payments ${ }^{d}$} \\
\hline Percentage of individuals incurring catastrophic health payments (income level) & $63 \%$ & $83 \%$ & 0.017 \\
\hline Percentage of individuals incurring catastrophic health payments (subsistence level) & $58 \%$ & $94 \%$ & $<0.001$ \\
\hline Percentage of individuals incurring catastrophic health payments (house-hold level) & $87 \%$ & $98 \%$ & 0.008 \\
\hline \multicolumn{4}{|c|}{$\begin{array}{l}\text { aFinancial catastrophe is defined as out of pocket payment for surgery which exceeds; } 20 \% \text { of the respondent's income, } 10 \% \text { of the household expenditures, or } \\
40 \% \text { of the household's net-food expenditures } \\
\text { bPercent of the respondent's annual income, house-hold expenditures, or subsistence expenditures that was spent on surgical care . i.e. the insured spent on } \\
\text { average } 40 \% \text { of their annual income on surgical care } \\
\text { 'Subsistence expenditures: Total annual household expenditures minus food expenditures } \\
\text { dPercentage of individuals incurring catastrophic health payments by insurance status at different catastrophic levels i.e. } 63 \% \text { of the insured incurred catastrophic } \\
\text { payments for surgical care at the income level }\end{array}$} \\
\hline
\end{tabular}

at KBTH to costs at other facilities as there have been no study to date on the cost of surgical care at other facilities in Ghana.

Another limitation is that we only captured patients requiring inpatient stay/admission; hence, our findings and costs would not be applicable for patients undergoing same-day or ambulatory surgery. We also are unable to capture the cost of foregone care, or delays in diagnosis and treatment, as our study only examined CHE(s) on a sample of patients who obtained surgical intervention at the hospital. We did not capture any associated costs for follow-up or readmissions for complications, although outpatient visits are paid for at capitated rates by NHIS [47], both of these would further drive up OOPE for patients.

Lastly, there might be limitations inherent in the survey technique used as it is often difficult to ask individuals to recall their income accurately, which may in some circumstances be seasonal or largely informal in LMICs [48, 49]. To account for this, we used the standardized GDHS and included three different catastrophic thresholds for which our results show internal consistency. We recognize that our study was not conducted at the household level, as is often the case in the GDHS, Ghana Living Standard Survey, and World Health Survey, but our target population was at the facility level [29, 50, 51]. Uniquely, our study provides the most sensitive and accurate cost estimates because we reviewed the actual cost of care to the patient at the facility. Prior studies in Ghana have been conducted through household surveys, which are limited by estimates of payments for health-care made by respondents and subject to recall bias [26, 27]. Those survey studies, however, also validate our findings of insured patients still at financial risk and paying out-of-pocket for services that are included in the scheme.

Our study findings lead us to offer several policy recommendations that could improve the equity in UHC as it relates to surgical care at KBTH. First, the calculated amount reimbursed for each surgical DRG is too low; in our study, the insurance paid on average $40 \%$ of the total cost of care and did not include many services. This feefor-service model based on the DRG in Ghana for inpatient services is a flat reimbursement scheme with no price caps on total expenditures. Consequently, the hospital can shift more costs not reimbursed by NHIS to the patient which can constitute up to $40 \%$ of a patient's annual income. This means of financing is not only regressive but also inconsistent with the core mission of the NHIS to provide a health insurance scheme that " adequately covers against the need to pay out of pocket at the point of service" [ 52]. Most health insurance schemes of high-income countries with an overall lower incidence of $\mathrm{CHE}(\mathrm{s})$ offer either no fees, a co-payment (a fixed amount for each covered service), co-insurance (a fixed percentage of the total claim amount), or a 
deductible (a fixed amount that patients must pay for services before insurance benefits apply). This is dependent on the benefit design and type of services provided, i.e., inpatient, outpatient, pharmacy [53-55]. Co-insurance typically ranges from $10 \%$ of inpatient cost in Japan and South Korea, to up to 30\% in countries within the Organization for Economic Co-operation and Development [54, 55]. Germany, Sweden, and Switzerland require a flat copayment of between (9-12 USD) per day for hospital stays [55]. The UK, Canada, and Norway require no co-payment for inpatient services utilized at accredited facilities [55]. Therefore, government strategies to: 1) improve the reimbursement rates for surgical care, and 2) institute cost-sharing for surgical conditions at KBTH that is equitable, would overall reduce out-of-pocket payments particularly for individuals who cannot afford to pay.

Secondly, efforts towards health equity should include efforts to better identify individuals who cannot afford to make payments. This could be improved through local identification systems with proxy means testing at the point of care. This is typically done at the enrollment phase in Ghana, as $60 \%$ of the insured population are exempt from paying the annual premiums. However, despite this, insured poor households are not exempt from making payments at the point of care. Examples from high income countries include Germany's health system, which provides a price cap whereby out-ofpocket cost should not exceed 1-2\% of the annual household income. England, France, Israel, Italy, Japan, Sweden, Switzerland, Norway, the Netherlands, and the United States provide exemptions from cost sharing for low income and specific populations [55-57]. Furthermore, enhancing efforts through the use of the existing social services in enrolling the uninsured at the point of care could offer a potential opportunity to expand the risk pool, thereby generating further revenue for the health insurance scheme.

\section{Conclusion}

This study-the first to analyze the impact of that National Health Insurance Scheme of Ghana on the cost of surgical care-shows that despite its benefits, surgery is still largely unaffordable for the majority of surgical patients seen at Korle-Bu Teaching Hospital. Though insured patients have greater financial risk protected than the uninsured, they continue making out-of-pocket payments for services that are intended to be included in the health insurance scheme. Greater than $50 \%$ of insured patients would face financial catastrophe to be able to receive surgical care. Our study summarizes the experience of the use of NHIS at a teaching hospital in Ghana, providing some evidence to guide policy reform in similar countries. Government-specific strategies to address these gaps in coverage are key to sustaining the mission of NHIS to provide universal health coverage inclusive of surgical care.

\section{Abbreviations}

CHE: Catastrophic health expenditure; G-DRG: Ghana's Diagnosis Related Grouping of the International Classification of Diseases 10th revision; KBTH: Korle-bu Teaching Hospital; LMIC: Low-and middle-income countries; NHIA: National Health Insurance Authority; NHIS: National Health Insurance Scheme of Ghana; OECD: Organization for Economic Co-operation and Development; OOP: Out of pocket payment; OOPE: Out of pocket expenditures; UHC: Universal health coverage; WHA: World Health Assembly; WHO: World Health Organization

\section{Acknowledgments}

The authors thank Pamela Derish, scientific editor in the UCSF Department of Surgery, for her editorial review.

\section{Authors' contributions}

$\mathrm{JO}$ and SE designed the study. JO and SE, oversaw its implementation. JO, DS, SE coordinated all research activities including the study design, recruitment, data collection, data analysis. JO and DS wrote the initial draft and $\mathrm{SE}, \mathrm{HH}, \mathrm{JW}, \mathrm{RR}$ contributed to the writing and editing of subsequent versions of the manuscript. All authors reviewed the study findings and read and approved the final version before submission.

\section{Authors' information}

This manuscript was prepared while JO was a U. S Fogarty Global Health Fellow through the University of California GLOCAL consortium and a research fellow at the Center of Surgery and Public Health-a joint program of Brigham and Women's Hospital, Harvard Medical School, and Harvard T.H. Chan School of Public Health, Boston, MA. She completed her fellowship year onsite at Korle-Bu Teaching Hospital, Accra, Ghana. DS is a doctoral student at the University of Ghana. SE is a consultant and lecturer at Korle-Bu Teaching Hospital. JW is the Deputy Chief Scientific Officer at the Center for Surgery and Public Health. HH is Chief and Professor of Surgery at the University of California San Francisco. RR is the director of Global Surgery Programs at the Brigham and Women's Hospital, Center for Surgery and Public Health.

\section{Funding}

Fogarty International Center and the Office of Research on Women's Health of the National Institute of Health (NIH) Maryland, United States under Award Number D43TW009343, as well as the University of California Global Health Institute (UCGHI), funded the corresponding author's time on the project. Neither the Fogarty International Center, Office of Research on Women's Health, or UCGHI have a role in the study design, data collection, analysis, data interpretation or writing of the report. The content is solely the responsibility of the authors and does not necessarily represent the official views of the $\mathrm{NIH}$ or UCGHI. The corresponding author had full access to all the data in the study and had final responsibility for the decision to submit for publication.

\section{Availability of data and materials}

The data that support the findings of this study are available from the corresponding author but restrictions apply because these data were used under license for the current study and are not publicly available. Data are, however, available from the authors upon reasonable request and with permission from Korle-Bu Teaching Hospital Ethical Committee and Institutional Review Board.

\section{Ethics approval and consent to participate}

This study received ethical approval from: 1) the University of California San Francisco Office of Ethics and Compliance, Human Research Protection Program 16-20541 and 2) Korle-Bu Teaching Hospital Ethical Committee and Institutional Review Board KBTH-STC 000742016. Informed consent was obtained in verbal format in the participant's language and approved by the ethics committee for the interviews. 


\section{Competing interests}

The authors declare that they have no competing interest.

\section{Author details}

'Brigham and Women's Hospital, Center for Surgery and Public Health, Boston, MA, USA. ²Department of Surgery, Korle-Bu Teaching Hospital, Accra, Ghana. ${ }^{3}$ National Institute of Health, Fogarty International Center- GLOCAL Consortium, Bethesda, USA. ${ }^{4}$ Department of Surgery, University of Alabama, 1720 2nd Ave S KB 217, Birmingham, AL 35294-0016, USA. ${ }^{5}$ University of Ghana, Accra, Ghana. ${ }^{6}$ Dodowa Health Research Centre, Accra, Ghana. ${ }^{7}$ Department of Surgery, University of California San Francisco, San Francisco, CA, USA.

Received: 1 June 2019 Accepted: 31 December 2019

Published online: 17 January 2020

\section{References}

1. Alkire BC, Shrime MG, Dare AJ, Vincent JR, Meara JG. Global economic consequences of selected surgical diseases: a modelling study. Lancet Glob Heal. 2015;3(S2):S21-7.

2. Debas HT, Gosselin R, McCord C, Jamison DT, Breman JG, Measham AR. Disease control priorities in developing countries. 2nd ed. Washington, DC: World Bank; 2006.

3. Anderson JE, Erickson A, Funzamo, et al. Surgical conditions account for the majority of admissions to three primary referral hospitals in rural Mozambique. World J Surg. 2014:38:823-9.

4. Groen RS, Samai M, Stewart KA, et al. Untreated surgical conditions in Sierra Leone: a cluster randomized, cross-sectional, countrywide survey. Lancet. 2012:380:1082-7.

5. Shrime MG, Dare A, Alkire B, O'Neill K, Meara JG. Catastrophic expenditure to pay for surgery: a modelling study. Lancet Glob Health. 2015;3:S38-44.

6. World Health Assembly. Strengthening emergency and essential surgical care and anesthesia as a component of universal health coverage. Retrieved April 28, 2018, from http://apps.who.int/gb/ebwha/pdf_files/WHA68/A68_ R15-en.pdf. Accesed 28 Apr 2018.

7. Alam K, Mahal A. Economic impacts of health shocks on households in low and middle-income countries: A review of the literature. Vol. 10, Globalization and Health. 2014. Retrieved April 20, 2018 from https:// globalizationandhealth.biomedcentral.com/articles/10.1186/1744-8603-10-21. Accessed 20 Apr 2018.

8. Chankova S, Sulzbach S, Diop F. Impact of mutual health organizations: evidence from West Africa. Health Policy Plan. 2008:23(4):264-76.

9. Lagomarsino G, Garabrant A, Adyas A, Muga R, Otoo N. Moving towards universal health coverage: Health insurance reforms in nine developing countries in Africa and Asia. Lancet. 2012;380:933-43.

10. Meara JG, AJM L, Hagander L, Alkire BC, Alonso N, Ameh EA, et al. Global Surgery 2030: Evidence and solutions for achieving health, welfare, and economic development. Lancet. 2015;386:569-624.

11. Agyepong IA, Adjei S. Public social policy development and implementation: a case study of the Ghana National Health Insurance scheme. Health Policy Plan. 2008;23(2):150-60.

12. Sylvester A. Mensah "National Health Insurance Scheme in Ghana: Reforms \&Achievements." Proc. of Ghana 10th Anniversary Conference, Ghana, Accra. N.p., 2014. Web. 15 Aug. 2016.

13. Witter S, Garshong B. Something old or something new? Social health insurance in Ghana. BMC Int Health Hum Rights. 2009;9:20. https://doi.org/ 10.1186/1472-698X-9-20

14. Blanchet NJ, Fink G, Akoto IO. The effect of Ghana's National Health Insurance Scheme on health care utilization. Ghana Med J. 2012:46(2):76-84.

15. Bonfrer I, Breebaart L, Van de Poel E. The Effects of Ghana's National Health Insurance Scheme on Maternal and Infant Health Care Utilization. PLoS ONE. 2016;11(11):e0165623. https://doi.org/10.1371/journal.pone.0165623

16. Duku SKO, van Dullemen CE, Fenenga C. Does Health Insurance Premium Exemption Policy for Older People Increase Access to Health Care? Evidence from Ghana. J Aging Soc Policy. 2015;27(4):331-47. https://doi.org/10.1080/ 08959420.2015 .1056650$.

17. Nsiah-Boateng E, Aikins M. Trends and characteristics of enrolment in the National Health Insurance Scheme in Ghana: a quantitative analysis of longitudinal data. Glob Health Res Policy. 2018;3:1-10.

18. Alhassan RK, Nketiah-Amponsah E, Arhinful DK. A review of the national health insurance scheme in Ghana: What are the sustainability threats and prospects? PLoS One. 2016;11(11):e0165151. https://doi.org/10.1371/journal. pone. 0165151

19. McIntyre D, Garshong B, Mtei G, Meheus F, Thiede M, Akazili J, et al. Beyond fragmentation and towards universal coverage: insights from Ghana, South Africa and the United Republic of Tanzania. Bull World Health Organ. 2008; 86(11):871-6

20. Ghana Health Service. 2013 Annual Report. Accra: Ghana Health Service; 2013.

21. Dixon J, Tenkorang EY, Luginaah IN, Kuuire VZ, Boateng GO. National health insurance scheme enrolment and antenatal care among women in Ghana: is there any relationship? Trop Med Int Heal. 2014;19(1):98-106.

22. Owoo NS, Lambon-Quayefio MP. National health insurance, social influence and antenatal care use in Ghana. Health Econ Rev. 2013;3(1):1-12.

23. Mensah J, Oppong J, Schmidt C. Ghana's National Health Insurance Scheme in the context of the health Mdgs: an empirical evaluation using propensity score matching. Health Econ. 2010;19:95-106.

24. Lambon-Quayefio MP, Owoo NS. Examining the influence of antenatal care visits and skilled delivery on neonatal deaths in Ghana. Appl Health Econ Health Policy. 2014;12(5):511-22.

25. Brugiavini A, Pace N. Extending health insurance in Ghana: effects of the National Health Insurance Scheme on maternity care. Health Econ Rev. 2016:6(1):1-10.

26. Kusi A, Hansen KS, Asante FA, et al. Does the National Health Insurance Scheme provide financial protection to households in Ghana? BMC Health Serv Res. 2015;15(1):331. https://doi.org/10.1186/s12913-015-0996-8.

27. Okoroh J, Essoun S, Seddoh A, Harris H, Weissman JS, Dsane-Selby L, et al. Evaluating the impact of the national health insurance scheme of Ghana on out of pocket expenditures: a systematic review. BMC Health Serv Res. 2018 18(1):426. https://doi.org/10.1186/s12913-018-3249-9.

28. Korle-bu Hospital (2016). Korle-bu Teaching Hospital 2016 Annual Report. Retrieved May 6, 2018, from http://kbth.gov.gh/assets/downloads/pdf/2016_ Annual_Report.pdf. Accessed 6 May 2018.

29. Ghana Statistical Service (GSS), Ghana Health Service (GHS), and ICF International. Ghana demographic and health survey 2014. Rockville: GSS, GHS, and ICF International; 2015.

30. Sullivan KM, Dean A, Minn MS. OpenEpi: A web-based epidemiologic and statistical calculator for public health. Public Health Rep. 2009;124:471-4.

31. Xu K, Evans DB, Kawabata K, et al. Household catastrophic health expenditure: a multicountry analysis. Lancet. 2003;362:111-7.

32. Wagstaff A, Van Doorslaer E. Catastrophe and impoverishment in paying for health care: with applications to Vietnam 1993-1998. Health Econ. 2003;12: 921-34

33. Flores G, Krishnakumar J, O'Donnell O, Van Doorslaer E. Coping with healthcare costs: implications for the measurement of catastrophic expenditures and poverty. Health Econ. 2008;17(12):1393-412. https://doi.org/10.1002/hec.1338.

34. Van Doorslaer $\mathrm{E}, \mathrm{O}$ 'Donnell $\mathrm{O}$, Rannan-Eliya RP, et al. Catastrophic payments for health care in Asia. Health Econ. 2007;16:1159-84.

35. O'Donnell O, Van Doorslaer E, Wagstaff A, Lindelow M. Analyzing health equity using household survey data: a guide to techniques and their implementation. Washington, D.C: World Bank; 2008.

36. Ghana Statistical Service (GSS), Ghana Health Service (GHS) Provisional 2016 Annual Gross Domestic Product Retrieved May 6, 2018 from http://www. statsghana.gov.gh/docfiles/GDP/GDP2017/April/Annual_2016_GDP_April\%2 02017_Edition.pdf

37. World Health Organization. Health Financing Working Paper. Spending targets for health: No magic number. (2017, February 17). Retrieved May 6, 2018 from http://www.who.int/health_financing/documents/no-magic-number/en/

38. World Health Organization. (2010). The World Health Report 2010. Health Systems Financing: The Path to Universal Coverage. https://doi.org/ISBN 978 9240684805

39. National Health Insurance Scheme. What you need to know about NHIS medicines. Retrieved May 8, 2018 from http://www.nhis.gov.gh/News/whatyou-need-to-know-about-nhis-medicines-list-4130

40. National Health Insurance Scheme. Essential Medicines List. Retrieved May 7 , 2018 from http://www.nhis.gov.gh/files/Medicines_List.pdf

41. National Health Insurance Scheme. Benefits package. Retrieved May 7, 2018 from http://www.nhis.gov.gh/benefits.aspx

42. Ghana Web. Korle-bu Reject NHIS Cards. Retrieved May 6, 2018 from https:// www.ghanaweb.com/GhanaHomePage/NewsArchive/Korle-Bu-rejects-NHIScards-254750

43. Agyepong IA, Aryeetey GC, Nonvignon J, Asenso-Boadi F, Dzikunu H, Antwi $E$, et al. Advancing the application of systems thinking in health: Provider 
payment and service supply behavior and incentives in the Ghana National Health Insurance Scheme - a systems approach. Heal Res Policy Syst. 2014; 12(1).

44. NHIA (2013). National Health Insurance Authority 2013 annual report. Retrieve may 6, 2018, from http://www.nhis.gov.gh/files/2013 annual reportfinal ver 29.09.14.Pdf

45. Kruk ME, Goldmann E, Galea S. Borrowing and selling to pay for health care in low- and middle-income countries. Health Aff. 2009;28(4):1056-66.

46. Leive A, Xu K. Coping with out-of-pocket health payments: empirical evidence from 15 African countries. Bull World Health Organ. 2008;86(11): 849-56.

47. NHIS. Provider Payment Mechanism Capitation. Retrieved June 25, 2018 from http://www.nhis.gov.gh/capitation.aspx

48. Howe LD, Galobardes B, Matijasevich A, Gordon D, Johnston D, Onwujeke $\mathrm{O}$, et al. Measuring socio-economic position for epidemiological studies in low- and middle-income countries: a method of measurement in epidemiology paper. Int J Epidemiol. 2012;41(3):871-86.

49. Sweeney S, Vassall A, Foster N, Simms V, Ilboudo P, Kimaro G, Mudzengi D, Guinness L. Methodological Issues to Consider When Collecting Data to Estimate Poverty Impact in Economic Evaluations in Low-income and Middle-income Countries. Health Econ. 2016;25:42-52. https://doi.org/10. 1002/hec.3304.

50. Ghana Statistical Service (2013). Ghana living standards survey 6 with labor force module (GLSS6/LFS). Ghana Statistical Service, 86(11), 871-876. doi: https://doi.org/10.1007/s13398-014-0173-7.2.

51. World Health Organization, World Health Survey. Retrieved May 7, 2018 from http://www.who.int/healthinfo/survey/instruments/en/

52. Government of Ghana. National Health Insurance Policy Framework, 2003. http://www.moh.gov.gh/wp-content/uploads/2016/02/National-HealthInsurance-Policy-framework.pdf. Accessed Dec, 2017

53. Xu K, Evans DB, Carrin G, Aguilar-Rivera AM, Musgrove P, Evans T. Protecting households from catastrophic health spending. Health Aff. 2007;26(4):972-83.

54. Hossein Z, Gerard A. Trends in cost sharing among selected high-income countries-2000-2010. Health Policy (New York). 2013;112(1-2):35-44.

55. The Commonwealth Fund. 2015 International Profiles of Health Care Systems. Retrieved May 5, 2018 from http://www.commonwealthfund. org/ /media/files/publications/fund-report/2016/jan/1857_mossialos_intl_ profiles_2015_v7.pdf

56. European Commission. Cost-Containment Policies in Hospital Expenditure in the European Union. (2016) Retrieved from May 5, 2018 from http://ec. europa.eu/economy_finance/publications/.

57. Mathauer I, Wittenbecher F. DRG-based payment systems in low- and middle-income countries: implementation experiences and challenges. Discussion Paper 2015. Retrieved May 6, 2018 from https://pdfs. semanticscholar.org/1dd8/deeef341b87a04287cb0d42ff5fd8b6cb15f.pdf

\section{Publisher's Note}

Springer Nature remains neutral with regard to jurisdictional claims in published maps and institutional affiliations.

Ready to submit your research? Choose BMC and benefit from:

- fast, convenient online submission

- thorough peer review by experienced researchers in your field

- rapid publication on acceptance

- support for research data, including large and complex data types

- gold Open Access which fosters wider collaboration and increased citations

- maximum visibility for your research: over $100 \mathrm{M}$ website views per year

At BMC, research is always in progress.

Learn more biomedcentral.com/submissions 